\title{
The Importance of Surface IrOx in Stabilizing RuO2 for Oxygen Evolution
}

Escribano, Maria Escudero; Pedersen, Anders Filsøe; Paoli, Elisa Antares; Frydendal, Rasmus; Friebel, Daniel; Malacrida, Paolo; Rossmeisl, Jan; Stephens, Ifan E L; Chorkendorff, Ib

Published in:

Journal of Physical Chemistry Part B: Condensed Matter, Materials, Surfaces, Interfaces \& Biophysical

Link to article, DOI:

10.1021/acs.jpcb.7b07047

Publication date:

2018

Document Version

Peer reviewed version

Link back to DTU Orbit

Citation (APA):

Escribano, M. E., Pedersen, A. F., Paoli, E. A., Frydendal, R., Friebel, D., Malacrida, P., Rossmeisl, J., Stephens, I. E. L., \& Chorkendorff, I. (2018). The Importance of Surface IrO in Stabilizing RuO for Oxygen Evolution. Journal of Physical Chemistry Part B: Condensed Matter, Materiałls, Surfaces, Interfaces \& Biophysical, 122(2), 947-955. https://doi.org/10.1021/acs.jpcb.7b07047

\section{General rights}

Copyright and moral rights for the publications made accessible in the public portal are retained by the authors and/or other copyright owners and it is a condition of accessing publications that users recognise and abide by the legal requirements associated with these rights.

- Users may download and print one copy of any publication from the public portal for the purpose of private study or research.

- You may not further distribute the material or use it for any profit-making activity or commercial gain

- You may freely distribute the URL identifying the publication in the public portal 


\title{
The Importance of Surface $\mathrm{IrO}_{x}$ in Stabilizing $\mathrm{RuO}_{2}$ for Oxygen Evolution
}

\author{
María Escudero-Escribano, ${ }^{*}, 1,2,3$ Anders F. Pedersen, ${ }^{2}$ Elisa A. Paoli, ${ }^{2}$ Rasmus Frydendal, ${ }^{2}$ Daniel \\ Friebel, ${ }^{3}$ Paolo Malacrida, ${ }^{2}$ Jan Rossmeisl, ${ }^{1}$ Ifan E. L. Stephens, ${ }^{*}, 2,4$ Ib Chorkendorff ${ }^{*}, 2$ \\ ${ }^{1}$ Nano-Science Centre, Department of Chemistry, University of Copenhagen, Universitetsparken 5, \\ DK-2100 Copenhagen, Denmark \\ ${ }^{2}$ Department of Physics, Fysikvej, Building 312, Technical University of Denmark (DTU), DK-2800 \\ Kgs. Lyngby, Denmark \\ ${ }^{3}$ SUNCAT Center for Interface Science and Catalysis, Department of Chemical Engineering, Stanford \\ University, 443 Via Ortega, Stanford, CA 94305, United States \\ ${ }^{4}$ Department of Materials, Imperial College London, 2.03b, Royal School of Mines, London SW72AZ, \\ England
}

\begin{abstract}
:
The high precious metal loading and high overpotential of the oxygen evolution reaction (OER) prevents the widespread utilization of polymer electrolyte membrane (PEM) water electrolyzers. Herein we explore the OER activity and stability in acidic electrolyte of a combined $\mathrm{IrO}_{\mathrm{x}} / \mathrm{RuO}_{2}$ system consisting of $\mathrm{RuO}_{2}$ thin films with sub-monolayer (1, 2 and $4 \AA$ ) amounts of $\mathrm{IrO}_{\mathrm{x}}$ deposited on top. Operando extended X-ray absorption fine structure (EXAFS) on the Ir L-3 edge revealed a rutile type $\mathrm{IrO}_{2}$ structure with some Ir sites occupied by $\mathrm{Ru}, \mathrm{IrO}_{\mathrm{x}}$ being at the surface of the $\mathrm{RuO}_{2}$ thin film. We monitor corrosion on $\mathrm{IrO}_{\mathrm{x}} / \mathrm{RuO}_{2}$ thin films by combining electrochemical quartz crystal microbalance (EQCM) with inductively coupled mass spectrometry (ICP-MS). We elucidate the importance of submonolayer surface $\mathrm{IrO}_{\mathrm{x}}$ in minimizing $\mathrm{Ru}$ dissolution. Our work shows that we can tune the surface properties of active OER catalysts such as $\mathrm{RuO}_{2}$, aiming to achieve higher electrocatalytic stability in PEM electrolyzers.
\end{abstract}




\section{INTRODUCTION}

There is an urgent need to develop a sustainable economy based on renewable energy., Electrocatalytic reactions taking place at energy conversion devices such as fuel cells and electrolyzers may play a key role in the transition towards a sustainable future. ${ }^{3}$ In particular, electrolysis of water allows the production of renewable hydrogen as an energy carrier. ${ }^{4-6}$ Polymer electrolyte membrane (PEM) electrolyzers are highly attractive due to their high efficiency, as they can operate at much higher current densities $\left(1-3 \mathrm{~A} \mathrm{~cm}^{-2}\right.$ ) than traditional alkaline electrolyzers (around $\left.0.2 \mathrm{~A} \mathrm{~cm}^{-2}\right){ }^{7-9}$ Furthermore, they are more amenable towards the small scale storage intermittent electricity from renewable resources. However, due to the acidic conditions at which PEM electrolyzers operate, the electrode materials at both anode and cathode are based on precious metals like Pt and Ir. ${ }^{7}$

The slow kinetics of the oxygen evolution reaction (OER) at the electrolyzer anode causes significant potential losses (overpotential). ${ }^{10,11}$ To date, only oxides based on Ir and Ru present reasonable activity and stability for OER in acidic electrolyte. ${ }^{12-18}$ High loadings of precious metal electrocatalysts are needed to minimize the overpotential, preventing the widespread utilization of PEM electrolyzers. In contrast, the cathodic reaction, the hydrogen evolution reaction (HER), has been widely investigated in the past decade. Negligible loadings of Pt can sustain enormous hydrogen evolution currents, ${ }^{19-22}$ and numerous electrode materials have been developed, including highly active non-precious metal catalysts based on sulfides and phosphides, ${ }^{23,24}$ although there are some stability issues here as well. ${ }^{25}$

In order to minimize the overpotential in oxygen electrocatalysis and design more efficient materials, we need to understand the activity and stability descriptors. ${ }^{4,26-29}$ The activity and stability of $\mathrm{RuO}_{2}$, the most active OER electrocatalyst, can vary dramatically as a function of the oxidation pre-treatment. Electrochemically (anodically) grown or plasma treated $\mathrm{RuO}_{2}$ catalysts are typically highly active for OER; however, they are less stable than thermally grown oxides. ${ }^{30-32}$ The stability of $\operatorname{IrO}_{\mathrm{x}}$ depends strongly on the synthesis conditions as well. ${ }^{33}$ Typically, $\mathrm{IrO}_{\mathrm{x}}$ has a lower catalytic activity than $\mathrm{RuO}_{\mathrm{x}}$; even so, it is less prone to corrosion. ${ }^{34-38}$ This prevents the use of pure $\mathrm{RuO}_{\mathrm{x}}$ at the PEM electrolyzer anode, $\mathrm{IrO}_{\mathrm{x}}$ being the catalyst of choice for large scale applications. ${ }^{7,39}$ Enhancing the catalytic stability is crucial to maximize the durability of PEM electrolyzers.

In the 1950s, Beer discovered efficient and stable transition metal oxides, the so-called dimensionally stable anodes (DSA $\left.{ }^{\circledR}\right),{ }^{40}$ which consisted of thermally decomposed oxides mixed with an activated metal, mainly Ir and $\mathrm{Ru}$, and deposited on an inert substrate, typically Ti. After the DSA ${ }^{\circledR}$ success, ${ }^{41}$ researchers have tried different combinations of metal oxides in order to find the optimal electrocatalyst compositon. ${ }^{5}$ In particular, both adding $\mathrm{IrO}_{\mathrm{x}}$ to $\mathrm{RuO}_{\mathrm{x}}$ and forming $\mathrm{Ru}$-Ir bimetallic oxides can result in a stability increase over $\mathrm{RuO}_{\mathrm{x}}{ }^{36,42-46}$ The activity and stability of Ru-Ir oxides are also very sensitive to the preparation method, since the surface enrichment of Ir and homogeneity of the phases varies depending on the preparation procedure. ${ }^{34,43-45}$

Experimental studies on $\mathrm{Ru}$-Ir mixed oxides show that $\mathrm{Ru}$ at the surface tends to dissolve, leaving an enriched Ir layer behind. ${ }^{36,47,48}$ However, the nature of the stabilizing effect is not fully understood yet. 
Thermodynamic stabilization under OER conditions is challenging. ${ }^{49}$ Consequently, Ir could provide kinetic stability against further dissolution of $\mathrm{RuO}_{2}$. The higher stability of $\mathrm{IrO}_{\mathrm{x}}$ as compared to $\mathrm{RuO}_{\mathrm{x}}$ have led theorists to study the surface segregation and migration energies of Ru-Ir mixed oxides and investigate alternative strategies to obtain highly active and stable OER catalysts. ${ }^{50}$ DFT calculations suggest that the active sites for OER on a rutile $\mathrm{RuO}_{2}(110)$ surface are terrace sites ${ }^{26}$ and dissolution takes place at under-coordinated sites. The calculated surface energies suggest that $\mathrm{IrO}_{\mathrm{x}}$ tends to sit on the surface under equilibrium conditions, since it has a lower surface energy. Moreover, Ir is most stable at the step edge sites of a stepped $\mathrm{RuO}_{2}(110)$ surface. This configuration is more stable than pure $\mathrm{RuO}_{2}$ because of the higher dissolution potential of $\mathrm{IrO}_{2} \cdot{ }^{51}$ This is in agreement with the work by Danilovic et al:: they vacuum annealed and thermally oxidized a bulk metallic Ir-Ru alloy; this treatment resulted in an Ir-rich oxide surface which was stable under oxygen evolution conditions. ${ }^{36} \mathrm{~A}$ similar effect was recently observed on $\mathrm{SrIrO}_{3}{ }^{16}$ where an $\mathrm{IrO}_{\mathrm{x}}$ overlayer was formed by leaching of Sr. These results are consistent with Man's proposal ${ }^{50}$ that surface $\mathrm{IrO}_{x}$ can stabilise a less stable oxide, which resides in the bulk. Even so, preparing oxides that are mixed in the bulk does not allow the precise control of the surface composition.

Understanding degradation mechanisms and quantifying the stability improvement of Ru-Ir mixed oxides is challenging. Thus far, the most common methods to study the stability have been short term electrochemical measurements, such as chronopotentiometry (at a constant current density) or chronoamperometry (at a constant potential) measurements. However, these tests cannot allow an estimation of the long-term catalytic performance. ${ }^{52,53}$ In contrast, combining electrochemical methods with in situ and operando studies can offer valuable information on the catalyst stability. ${ }^{31,47,53,54}$ Electrochemical quartz crystal microbalance (EQCM) allows following mass changes at the electrode. ${ }^{53}$ In addition, on-line elemental analysis can be performed by combining inductive couple plasma mass spectrometry (ICP-MS) with a scanning flow cell. ${ }^{35,55}$

In situ and operando spectroscopy is particularly suitable to study corrosion mechanisms and monitoring the reaction products under dynamic conditions. ${ }^{54,56}$ Synchrotron based X-ray techniques have become an essential tool to elucidate solid catalysts; ${ }^{57-60}$ Miquel Salmerón is a pioneer in this area. $^{54,61}$ In particular, (near) ambient pressure X-ray photoelectron spectroscopy (AP-XPS) and operando X-ray absorption spectroscopy (XAS) allow operando investigations of the chemical state and structure of the electrode surface and the reaction intermediates in oxygen electrocatalysis. ${ }^{47,59,62,63}$

This article combines EQCM and ICP-MS measurements to monitor mass losses and investigate the corrosion rate of sputtered $\mathrm{RuO}_{2}$ thin films decorated by sub-monolayer (1, 2 and $4 \AA$ ) amounts of $\operatorname{IrO}_{\mathrm{x}}$. Recently, we used a very similar approach to mildly stabilize $\mathrm{MnO}_{\mathrm{x}}$ films in acid under oxygen evolution conditions, using surface $\mathrm{TiO}_{x}{ }^{64}$ Herein, we have also used operando grazing incidence extended X-ray absorption fine structure (GI-EXAFS) on the $\mathrm{Ir}_{3}$ edge to show that the $\mathrm{IrO}_{\mathrm{x}}$ resides at the surface of the $\mathrm{RuO}_{2}$ thin film. The addition of sub-monolayer surface $\mathrm{IrO}_{\mathrm{x}}$ improves the stability of $\mathrm{RuO}_{2}$ thin films. 


\section{EXPERIMENTAL SECTION}

\subsection{Preparation of thin films}

The hybrid $\mathrm{IrO}_{\mathrm{x}} / \mathrm{RuO}_{2}$ thin films, as well as $40 \mathrm{~nm}$ thin films of pure $\mathrm{RuO}_{2}$ and $\mathrm{IrO}_{2}$ were fabricated by magnetron sputtering. ${ }^{53}$ Sub-monolayer amounts of $\mathrm{IrO}_{\mathrm{x}}$ were deposited on top of a $40 \mathrm{~nm} \mathrm{RuO}_{\mathrm{x}}$ thin film. Both films were deposited by sputtering of a $\mathrm{Ru}$ or Ir target at $30 \mathrm{~W}$ with the sample substrate being held at $300^{\circ} \mathrm{C}$. The oxide was formed during sputtering by a reactive atmosphere at $3 \mathrm{mTorr}$ and a flow of $10 \mathrm{sccm}$ Ar and $4 \mathrm{sccm} \mathrm{O}$. For $\mathrm{IrO}_{2}$ thin films, a pressure of $5 \mathrm{mTorr}$, and a flow of $20 \mathrm{sccm}$, of Ar and $5 \mathrm{sccm}$ of $\mathrm{O}_{2}$ was used, in order to assure the formation of crystalline $\mathrm{IrO}_{2}$. The sputter rate was monitored by a quartz crystal microbalance (QCM).

For the stability measurements, $40 \mathrm{~nm} \mathrm{RuO}_{2}$ thin films were deposited on an Au-coated electrochemical quartz crystal microbalance (EQCM), followed by the deposition of $1 \AA$, $2 \AA$, or $4 \AA$ of $\mathrm{IrO}_{\mathrm{x}}$. After the deposition, the substrate was held at $300^{\circ} \mathrm{C}$ for 30 minutes for annealing. For X-ray diffraction (XRD) characterization, the $\mathrm{RuO}_{2}$ and $\mathrm{IrO}_{2}$ thin films were deposited on a glass substrate, while for X-ray absorption spectroscopy (XAS) measurements the thin films were deposited on polycrystalline Au disks.

\subsection{Characterization methods}

The $40 \mathrm{~nm} \mathrm{RuO}_{2}$ thin film was structurally characterized by glancing angle X-ray diffraction (GAXRD) from a sample film on a glass substrate. A PAN Analytical X'Pert PRO Diffractometer was used, equipped with a $\mathrm{Cu} \mathrm{K} \alpha \mathrm{X}$-ray source with a wavelength of $1.54 \AA$ and a monochromator on the detector. The incidence angle was set to $0.5^{\circ}$. The thin film morphology was characterized by scanning electron microscopy (SEM) made with an acceleration voltage of $5.00 \mathrm{kV}$ and secondary electron detection using a Helios EBS3 microscope. $\mathrm{IrO}_{\mathrm{x}} / \mathrm{RuO}_{\mathrm{x}}$ thin films were examined by X-ray photoelectron spectroscopy (XPS). A Theta Probe system by Thermo Fischer was utilized, with a monochromatized $\mathrm{Al} \mathrm{K}_{\alpha} \mathrm{X}$-ray source. It is equipped with a hemispherical analyzer, which also allows angle-resolved XPS (AR-XPS) to be measured in the same system. ${ }^{29}$

\subsection{In situ $\mathrm{X}$-ray absorption synchrotron measurements}

Synchrotron measurements were carried out at Stanford Synchrotron Radiation Lightsource (SSRL) at SLAC National Accelerator Laboratory in California, USA. Grazing incidence extended X-ray absorption fine structure (GI-EXAFS) measurements were carried out at beam line 11-2, which is a hard X-ray wiggler beam line equipped with a $\operatorname{Si}(220)$ monochromator in the $\varphi=0^{\circ}$ setting. A 100 element Ge detector was used for fluorescence detection, while ion chambers were used for measuring initial and transmitted intensities. EXAFS was measured at the $\operatorname{Ir} \mathrm{L}_{3}$-edge $(11215 \mathrm{eV})$ on $1 \AA$ and $2 \AA$ $\mathrm{IrO}_{\mathrm{x}} / \mathrm{RuO}_{2} / \mathrm{GC}$ samples. The analysis was carried out using the SIXPack analysis software, and the fitting was done using scattering paths from FEFF6 calculations. A $\mathrm{k}^{2}$-weighted $\chi(\mathrm{k})$ function was used for fitting in the range of $3-9 \AA^{-1}$ using a Hanning filter. The fitting itself was done in R-space in the range $1.1-3.8 \AA$. 


\section{RESULTS AND DISCUSSION}

The aim of this work is to improve the stability of $\mathrm{RuO}_{2}$ by depositing sub-monolayer amounts of $\mathrm{IrO}_{\mathrm{x}}$ on top. Pure $\mathrm{RuO}_{2}$ and $\mathrm{IrO}_{2}$ thin films were prepared by reactive sputter deposition. ${ }^{53,64,66}$ Both thin films were structurally characterized by GA-XRD and SEM (see Supplementary Information, S.I., Figures S1-S4). According to SEM images (Figures S3-S4), $\mathrm{IrO}_{2}$ thin films present rougher surfaces than $\mathrm{RuO}_{2}$ thin films, exhibiting triangular-shape structures which protrude in the $\mathrm{z}$ direction. This could be explained by differences in the film growth during the sputter deposition. Stoerzinger et al. also observed differences in morphology on epitaxially grown $\mathrm{RuO}_{2}$ and $\mathrm{IrO}_{2}$ films; ${ }^{67} \mathrm{IrO}_{2}$ (100) films were almost 10 times rougher than $\mathrm{RuO}_{2}$ (100) films, while $\mathrm{IrO}_{2}$ (110) exhibited 4 times higher roughness than $\mathrm{RuO}_{2}$ (110) films. McCrory et al. observed much higher roughness for electrodeposited $\mathrm{IrO}_{2}$ as well, as compared to other non-noble metal oxides. ${ }^{13}$

Small amounts of $\mathrm{IrO}_{\mathrm{x}}$ were sputtered onto the surface $\mathrm{RuO}_{2}$ thin films to form the $\mathrm{IrO}_{\mathrm{x}} / \mathrm{RuO}_{2}$ surfaces. The nominal deposition thicknesses were 1,2, 4 and $10 \AA$. This provides a well-defined and wellcharacterized system onto which model studies can be carried out in order to understand the activity 
and stability trends, as well as quantify the stability enhancement. A monolayer of iridium oxide corresponds to $3.2 \AA \AA^{68}$ Assuming a conservative roughness factor of 2 for $\mathrm{RuO}_{2}$ thin films, it is unlikely that the surface is completely covered by $\mathrm{IrO}_{x}$, even when $4 \AA$ are deposited. Hence we consider 1, 2 and $4 \AA$ thick films to correspond to sub-monolayer additions.

In order to investigate bond distances and coordination numbers of neighboring atoms of the surface, we carried out operando GI-EXAFS measurements on the $\mathrm{Ir} \mathrm{L}_{3}$-edge of $\mathrm{IrO}_{\mathrm{x}} / \mathrm{RuO}_{2}$ thin films containing 1 and $2 \AA$ of $\operatorname{IrO}_{\mathrm{x}}$. Both samples were measured as-prepared ("dry"), and the $2 \AA \mathrm{IrO}_{\mathrm{x}} / \mathrm{RuO}_{2}$ sample was also measured in-situ with an applied potential of $1.0 \mathrm{~V}$ vs. RHE. Figure 1 shows the structure resulting from the fit to the EXAFS data, consisting of a rutile type $\mathrm{IrO}_{\mathrm{x}}$, with $\mathrm{Ru}$ occupying some of the Ir sites. Table 1 shows the fitted bond distances as well as the coordination numbers. Debye-Waller factors $\left(\sigma^{2}\right)$, overall energy tuning $\left(\Delta E_{0}\right)$, amplitude reduction factor $\left(S_{0}{ }^{2}\right)$, and goodness of fit parameters are shown in Table S1 in the Supporting Information (S.I.). Figure S5 shows the $k^{2}-$ weighted $\chi(k)$ and $\chi(R)$ extracted from the measured EXAFS spectra, as well as the fitted function. The range of k-space used for the Fourier transform is indicated as well as the fitting range in real space. During the fitting process, we were unable to distinguish between Ir and Ru neighbors, and we could not separate bond distances that were very close to each other. To avoid degeneracy between the coordination numbers, amplitude reduction factor, and Debye-Waller factors, the latter two were fixed during the fitting procedure. The Debye-Waller factors were tuned by hand to optimize the fit while maintaining physically reasonable values. The fitting analysis shows that the first coordination shell of $\mathrm{O}$ was fully occupied in all cases. The further coordination shells with $\mathrm{Ir} / \mathrm{Ru}$ and $\mathrm{O}$ show a smaller occupancy than bulk rutile $\mathrm{IrO}_{2}$. These results are consistent with $\mathrm{IrO}_{\mathrm{x}}$ being on the surface of the $\mathrm{RuO}_{2}$ thin film.

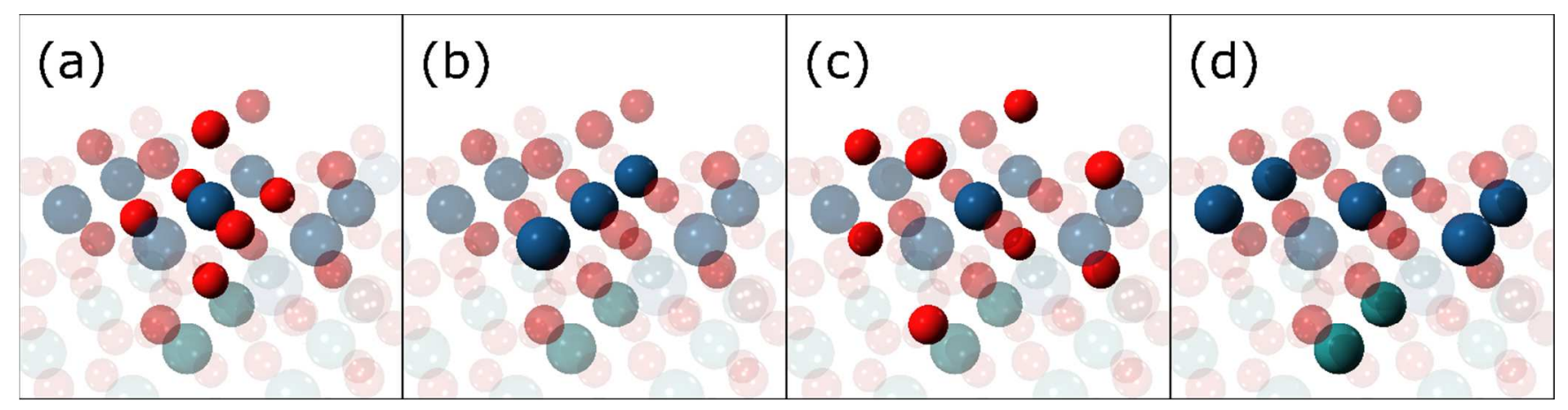

Figure 1. Schematic view of the structure consistent with the fitting of the EXAFS data, a rutile type $\mathrm{IrO}_{2}$ with some Ir sites occupied by $\mathrm{Ru}$. All the panels (a-d) show the full structure transparently, and the following atoms are highlighted: (a) the central absorbing $\mathrm{Ir}$ (blue) and the 6 surrounding $\mathrm{O}$ (red) making up the first oxygen coordination shell; (b) the two nearest Ir/Ru sites; (c) the $\mathrm{O}$ atoms making up the second $\mathrm{O}$ coordination shell; and (d) the second nearest $\mathrm{Ir} / \mathrm{Ru}$ sites, in this case also containing $\mathrm{Ru}$ (green). 
Table 1. EXAFS fitting results from $1 \AA$ and a $2 \AA \mathrm{IrO}_{\mathrm{x}}$ on $\mathrm{RuO}_{2}$ thin film. The bond distances (R) and coordination numbers $(\mathrm{N})$ are shown for the two dry samples, as well as the in situ measurement on the $2 \AA \mathrm{IrO}_{\mathrm{x}} / \mathrm{RuO}_{2}$ sample at $1.0 \mathrm{~V}$ vs. RHE. For comparison the bond distances and coordination numbers are shown for bulk rutile $\mathrm{IrO}_{2}$. The first coordination shell of both $\mathrm{O}$ and $\mathrm{Ir} / \mathrm{Ru}$ sites is fully occupied, whereas the second coordination shell has a lower occupancy than bulk $\mathrm{IrO}_{2}$, consistent with $\mathrm{IrO}_{\mathrm{x}}$ being at the surface.

\begin{tabular}{|l|l|l|l|l|l|l|l|l|}
\hline \multirow{2}{*}{ Sample } & \multicolumn{2}{c|}{ First oxygen } & \multicolumn{2}{c|}{ First Ir/Ru } & \multicolumn{2}{c|}{ Second oxygen } & \multicolumn{2}{c|}{ Second Ir/Ru } \\
\cline { 2 - 9 } & $\mathrm{R}_{1}[\AA]$ & $\mathrm{N}_{1}$ & $\mathrm{R}_{2}[\AA]$ & $\mathrm{N}_{2}$ & $\mathrm{R}_{3}[\AA]$ & $\mathrm{N}_{3}$ & $\mathrm{R}_{4}[\AA]$ & $\mathrm{N}_{4}$ \\
\hline $\begin{array}{l}1 \AA \mathrm{IrO}_{\mathrm{x}} / \mathrm{RuO}_{2} / \mathrm{GC} \\
(\mathrm{Dry})\end{array}$ & $1.98 \pm 0.02$ & $5.5 \pm 0.5$ & $3.09 \pm 0.09$ & $2.1 \pm 2.3$ & $3.55 \pm 0.08$ & $5.2 \pm 2.6$ & $3.57 \pm 0.05$ & $3.8 \pm 2.2$ \\
\hline $\begin{array}{l}2 \AA \mathrm{IrO}_{\mathrm{x}} / \mathrm{RuO}_{2} / \mathrm{GC} \\
(\mathrm{Dry})\end{array}$ & $1.98 \pm 0.01$ & $5.6 \pm 0.3$ & $3.11 \pm 0.05$ & $3.1 \pm 1.8$ & $3.54 \pm 0.06$ & $4.3 \pm 1.9$ & $3.56 \pm 0.03$ & $4.2 \pm 1.6$ \\
\hline $2 \AA \mathrm{IrO}_{\mathrm{x}} / \mathrm{RuO}_{2} / \mathrm{GC}(1 \mathrm{~V})$ & $2.01 \pm 0.04$ & $6.1 \pm 1.3$ & $3.14 \pm 0.12$ & $5.7 \pm 9.7$ & $3.64 \pm 0.33$ & $4.0 \pm 8.3$ & $3.50 \pm 0.13$ & $4.3 \pm 9.0$ \\
\hline${\mathrm{Bulk} \mathrm{IrO}_{2}}$ & $1.96-2.00$ & 6 & 3.16 & 2 & $3.41-3.72$ & 8 & 3.56 & 8 \\
\hline
\end{tabular}

The $\mathrm{IrO}_{\mathrm{X}} / \mathrm{RuO}_{2}$ thin films with a nominal deposition of $10 \AA$ were characterized by monochromatized XPS. Figure 2 shows the XPS spectra of Ru $3 \mathrm{~d}$ (Figure $2 \mathrm{a}$ ) and Ir $4 \mathrm{f}$ (Figure $2 \mathrm{~b}$ ) core level regions. The XPS spectra with variable nominal $\mathrm{IrO}_{\mathrm{x}}$ deposition exhibit similar peak shapes. For both $\mathrm{Ru} 3 \mathrm{~d}$ and $\mathrm{Ir}$ 4f, the peaks positions attest the presence of the valence state IV. The fitting reveals that the metallic component is zero, only the oxides of Ru and Ir being present at the surface. The XPS spectra exhibit the characteristic features for $\mathrm{RuO}_{2}$ and $\mathrm{IrO}_{2}$, with the pair of doublets for the main peak and the satellite. ${ }^{69,70}$ In all cases, the $\mathrm{Ru} 3 \mathrm{~d}$ and $\mathrm{Ir} 4 \mathrm{f}$ peaks could be fitted with fixed positions and similar intensity ratios, suggesting that the chemical phase is not changing among samples with different nominal thicknesses of $\mathrm{IrO}_{\mathrm{x}}$. Moreover, the peaks do not change for XPS spectra taken at different emission angles, indicating a good homogeneity of the samples.

The depth profile from angle-resolved XPS with the atomic concentration as a function of the depth on the $10 \AA \mathrm{IrO}_{\mathrm{x}} / \mathrm{RuO}_{2}$ thin films is illustrated in Figure 3. As can be observed, AR-XPS revealed that these surfaces do not present Ru on the topmost layers, confirming that the surface is covered with Ir as deposited. We note that the appearance of a $\mathrm{C}$ signal in Figure 3 is presumably due to adventitious carbon accumulated on the surface of the $\mathrm{IrO}_{\mathrm{x}} / \mathrm{RuO}_{2}$ thin films after air exposure. This is in agreement with the $\mathrm{C}$ 1s peak present in Figure 2a. The intensity of the $\mathrm{C} 1 \mathrm{~s}$ peak was determined by imposing the 3:2 intensity ratio of the $\mathrm{Ru} 3 \mathrm{~d}$ doublets; the position of the $\mathrm{C} 1 \mathrm{~s}$ peak resulting from the fit is also compatible with adventitious carbon and it was not found to vary significantly with different angles, indicating a good reliability of the fit. 

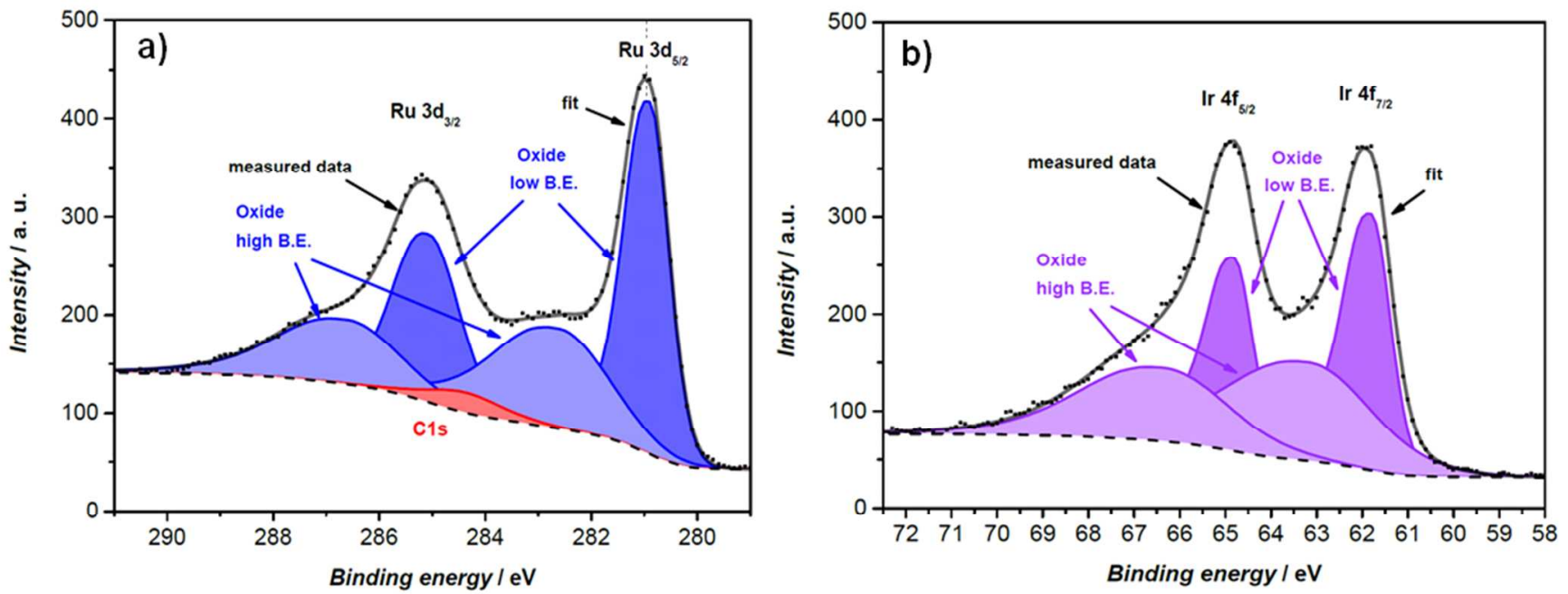

Figure 2. XPS spectrum of a $\mathrm{RuO}_{2}$ thin film modified with $10 \AA \mathrm{IrO}_{2}$ taken at $21^{\circ}$ emission angle: (a) XPS spectrum of Ru 3d core level region; (b) XPS spectrum of Ir 4f core level region.

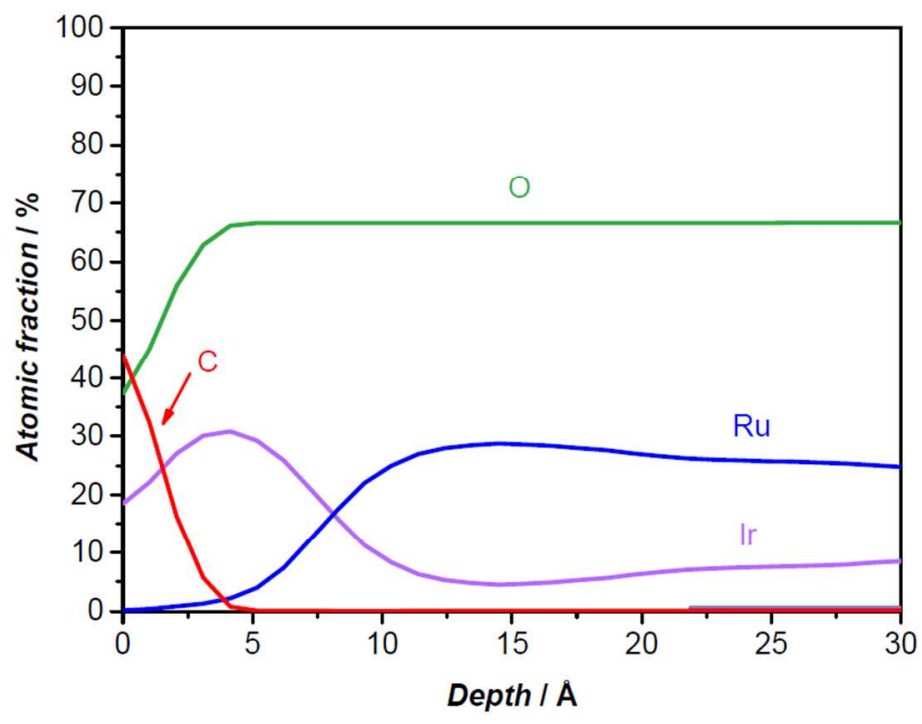

Figure 3. Depth profile of the surface modified $10 \AA \mathrm{IrO}_{2}$ on $\mathrm{RuO}_{2}$ thin film evaluated using AR-XPS.

The OER activity was measured by quasi stationary cyclic voltammetry (CV) in $\mathrm{N}_{2}$-saturated $0.05 \mathrm{M}$ $\mathrm{H}_{2} \mathrm{SO}_{4}$ in the EQCM set-up. Figure 4 shows the CVs showing the OER activity as the geometric current density as a function of the $\mathrm{iR}$-corrected potential versus the reversible hydrogen electrode (RHE) on a $40 \mathrm{~nm} \mathrm{RuO}_{2}$ thin film, as well as $\mathrm{RuO}_{2}$ thin films with 1, 2, and $4 \AA$ of $\mathrm{IrO}_{\mathrm{x}}$ deposited on 
the surface. The inset shows the overpotential required to reach a current density of $5 \mathrm{~mA} / \mathrm{cm}^{2}$. The bare $\mathrm{RuO}_{2}$ thin film is most active with an overpotential of $360 \mathrm{mV}$, and the more $\mathrm{IrO}_{\mathrm{x}}$ on the surface the higher overpotential is measured up to $410 \mathrm{mV}$ for $4 \AA \mathrm{IrO}_{\mathrm{x}} / \mathrm{RuO}_{2}$. This is in agreement with earlier works on mixtures of Ir and $\mathrm{Ru}$ oxides for OER showing a decrease in the activity when Ir is present. ${ }^{36,42-44}$ Notably, a significant drop in activity of $40 \mathrm{mV}$ at $5 \mathrm{~mA} \mathrm{~cm}{ }^{-2}$ occurs when adding $1 \AA$ of $\mathrm{IrO}_{2}$ to the $\mathrm{RuO}_{2}$ thin film. Although the overpotential increases with the amount of deposited $\mathrm{IrO}_{x}$, the activity drop becomes less pronounced for 2 and $4 \AA$ of $\mathrm{IrO}_{2} / \mathrm{RuO}_{2}$. This behavior differs significantly from the linear relationship of the overpotential at $0.1 \mathrm{~mA} \mathrm{~cm}^{-2}$ observed by Kötz et al. ${ }^{42}$

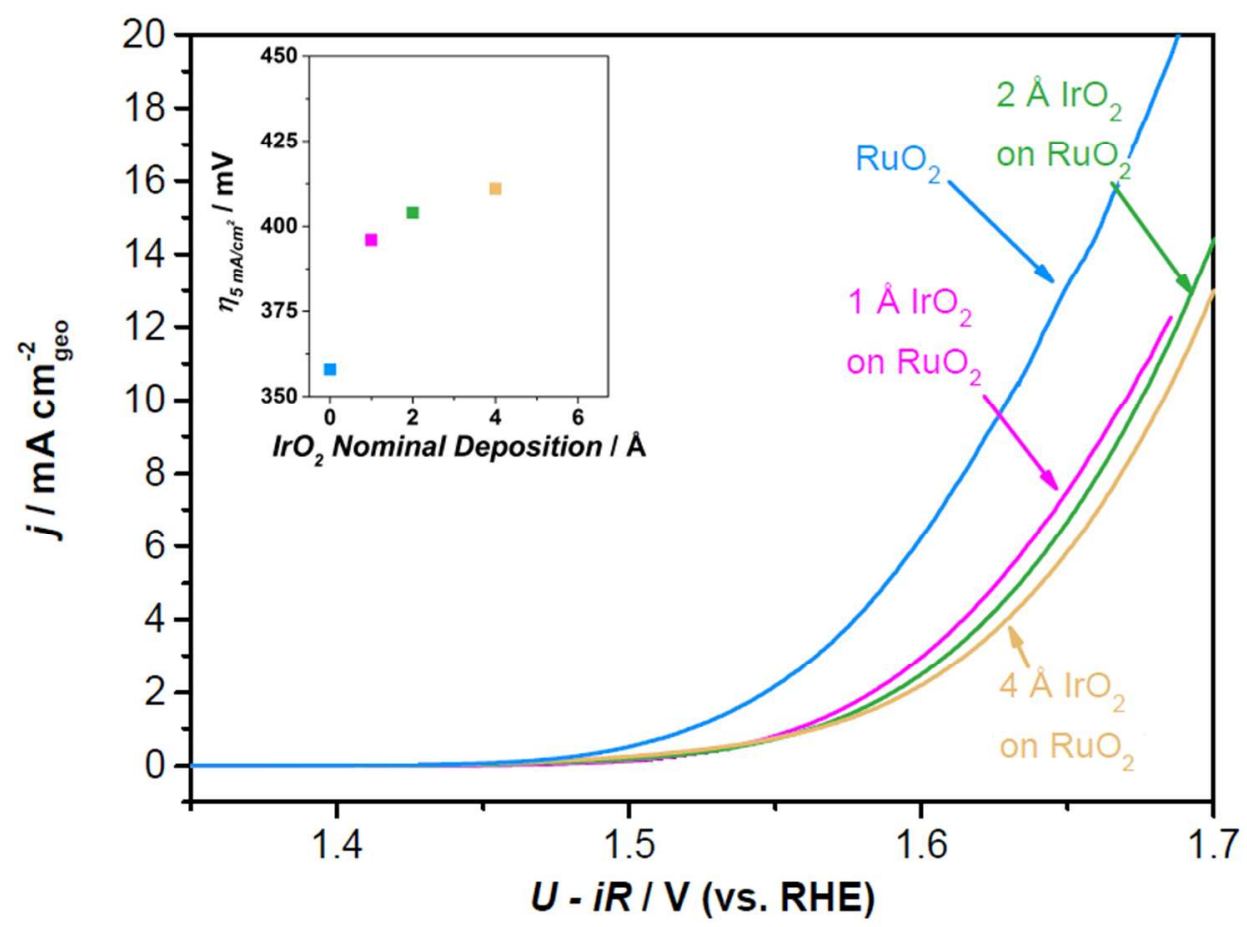

Figure 4. Quasi stationary CVs in the EQCM set-up showing the geometric current density as a function of the potential for a $40 \mathrm{~nm} \mathrm{RuO}_{2}$ thin film as well as $\mathrm{RuO}_{2}$ thin films with 1,2 and $4 \AA$ of $\mathrm{IrO}_{\mathrm{x}}$ on the surface. The inset shows the overpotential required to reach a current density of $5 \mathrm{~mA} \mathrm{~cm}{ }^{2}$ versus the $\mathrm{IrO}_{2}$ nominal deposition (in $\AA$ ). The $\mathrm{CVs}$ were recorded in $\mathrm{N}_{2}$-saturated $0.05 \mathrm{M} \mathrm{H}_{2} \mathrm{SO}_{4}$ and at $5 \mathrm{mV} \mathrm{s}^{-1}$.

In order to investigate the stability enhancement of the surface-modified $\mathrm{RuO}_{2}$ thin films, the $\mathrm{IrO}_{\mathrm{x}} / \mathrm{RuO}_{\mathrm{x}}$ thin films were deposited on Au-covered EQCM substrates. We first studied the stability under potentiostatic conditions. ${ }^{53}$ Figure $\mathrm{S} 6$ shows the current density and mass losses of $\mathrm{RuO}_{2}$ and $2 \AA$ $\mathrm{IrO}_{\mathrm{x}}$ onto $\mathrm{RuO}_{2}$ thin films after a two-hour chronoamperometry test at $1.8 \mathrm{~V}$ vs. RHE. In this case, we could not observe any effect on the stability by adding surface $\mathrm{IrO}_{\mathrm{x}}$. After one hour, the $\mathrm{IrO}_{\mathrm{x}} / \mathrm{RuO}_{\mathrm{x}}$ thin films behave like pure $\mathrm{RuO}_{2}$ thin films. We can speculate that the surface Ir atoms did not diffuse to the undercoordinated sites of the $\mathrm{RuO}_{2}$ surface when the thin films were prepared. Another possible 
explanation could be that the corrosion of $\mathrm{RuO}_{2}$ is so fast at $1.8 \mathrm{~V}$ vs. RHE that we cannot see any stability effect by addition of sub-monolayer amounts of surface $\mathrm{IrO}_{\mathrm{x}}$.

We carried out CVs before the chronoamperometry, to investigate whether this allowed diffusion towards undercoordinated sites. Figure S7 shows little stabilizing effect after an hour test on the chronoamperometric tests after cycling either. However, during the initial potentiodynamic test, we could observe some improvements. This could indicate that potential cycling can help $\operatorname{Ir}$ to the undercoordinated sites.

After performing the stability tests under potentiodynamic conditions (Figures S6 and S7), we carried out stability tests under dynamic conditions. We measured the mass loss of $\mathrm{IrO}_{\mathrm{x}} / \mathrm{RuO}_{2}$ thin films as well as pure $\mathrm{RuO}_{2}$ and $\mathrm{IrO}_{2}$ thin films, for comparison, while the potential was continuously cycled in an accelerated stress test. The potential was cycled from 1.23 to $1.80 \mathrm{~V}$ vs. RHE in $\mathrm{N}_{2}$-saturated electrolyte. Figure 5a shows the geometric current density at $1.8 \mathrm{~V}$ versus time as a function of the time during the nine-hour test under dynamic operations. In parallel, the EQCM mass losses were recorded as a function of time during that test, as shown in Figure 5b. A positive effect due to the addition of surface $\mathrm{IrO}_{\mathrm{x}}$ to $\mathrm{RuO}_{2}$ thin films can be clearly observed now. The total mass decreases continuously for the bare $\mathrm{RuO}_{2}$ thin film due to its poor stability. In contrast, all the measured $\mathrm{IrO}_{\mathrm{x}} / \mathrm{RuO}_{2}$ films seem to be rather stable. Notably, thin films covered with only $1 \AA$ of $\mathrm{IrO}_{\mathrm{x}}$ exhibit a drastic improvement in stability as compared to $\mathrm{RuO}_{2}$. Further addition of $\operatorname{IrO}_{\mathrm{x}}(2 \AA)$ induce slight additional improvements. The behaviour of $4 \AA \mathrm{IrO}_{\mathrm{x}} / \mathrm{RuO}_{2}$ thin films over the $9 \mathrm{~h}$ stability test is different from the other surfacemodified thin films studied in this work, showing a mass gain over time. Pure $\mathrm{IrO}_{2}$ exhibited a similar (although less pronounced) behavior. This may be related to the ability of the EQCM to adapt its properties while the potential is cycled.
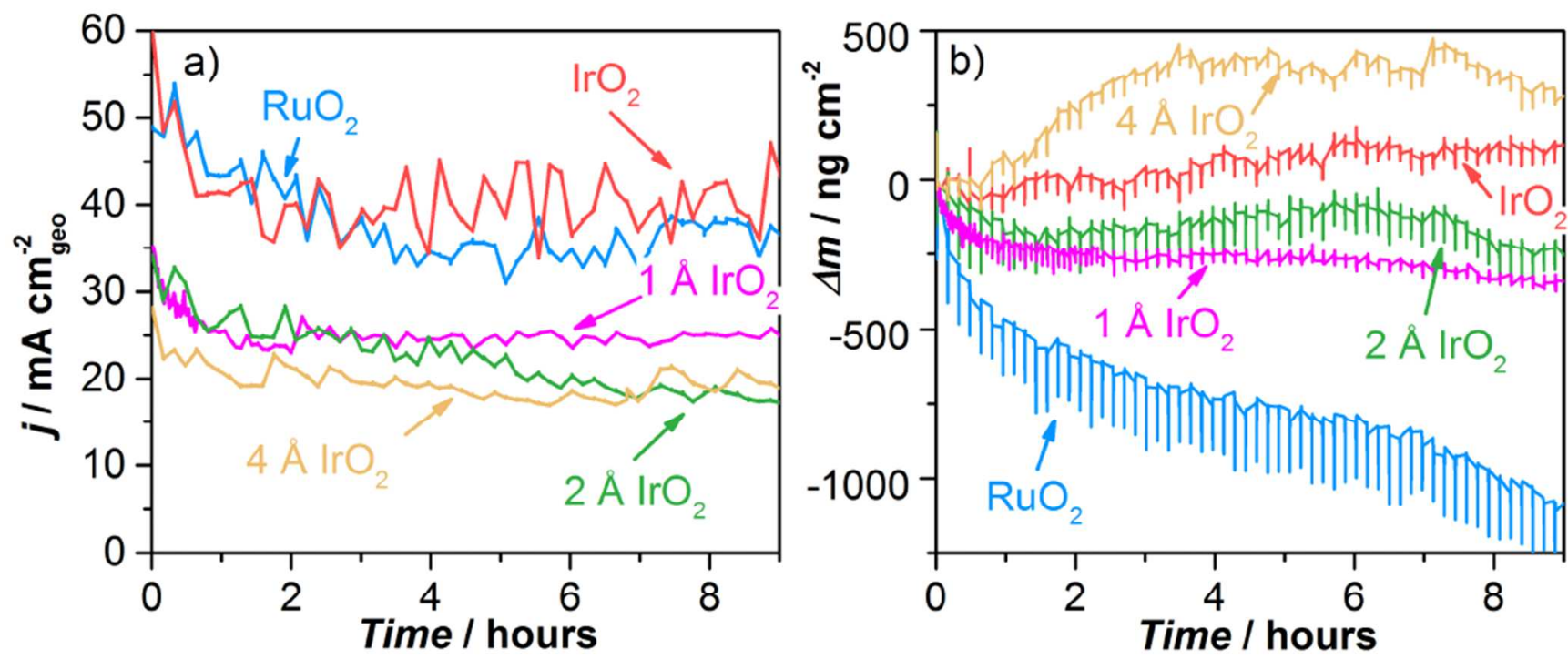

Figure 5. EQCM measurements while the potential is cycled from 1.23 to $1.80 \mathrm{~V}$ vs. RHE at $20 \mathrm{mV} \mathrm{s}^{-1}$ in $\mathrm{N}_{2}$-saturated $0.05 \mathrm{M} \mathrm{H}_{2} \mathrm{SO}_{4}$ at room temperature for pure $\mathrm{RuO}_{2}$ and $\mathrm{IrO}_{2}$ thin films as well as 1,2 
We can hypothesize that the $\mathrm{RuO}_{2}$ does not only corrode at the undercoordinated sites. For instance, if the undercoordinated sites were a factor 100 less stable than the terraces, a two-hour stability test at $1.8 \mathrm{~V}$ vs. RHE would also induce the corrosion at the terraces. In contrast, if we cycled between 1.23 and $1.8 \mathrm{~V}$ vs. RHE for 2 hours, we would only spend $10 \mathrm{~min}$ in the potential region above $1.75 \mathrm{~V}$ vs. RHE, and 20 min above $1.70 \mathrm{~V}$ vs. RHE, which would be equivalent to only $8 \%$ and $16 \%$ of the total time of the stability test, respectively.

We note that capacitance measurements ${ }^{13,71}$ revealed a much higher double layer capacitance for 40 $\mathrm{nm} \mathrm{IrO}_{2}$ thin films than $40 \mathrm{~nm} \mathrm{RuO}_{2}$ thin films as well as polycrystalline $\mathrm{RuO}_{2}$ and $\mathrm{IrO}_{2}$ electrodes, ${ }^{66}$ for comparison (see Figure S8 in the S.I.). This suggests that $\mathrm{IrO}_{2}$ thin films exhibits a much rougher surface, in agreement with SEM images (Figure S4), and consistent with the literature. ${ }^{13,67}$ In contrast, $\mathrm{RuO}_{2}$ thin films have a very low roughness, close to polycrystalline $\mathrm{RuO}_{2}{ }^{66}$ We hypothesize that submonolayer amounts of $\mathrm{IrO}_{\mathrm{x}}$ on $\mathrm{RuO}_{2}$ thin films are smoother than a pure $\mathrm{IrO}_{2}$ thin film, due to favorable interactions between the film and the surface.

To study and quantify the corrosion rate for $\mathrm{RuO}_{2}$ and $\mathrm{IrO}_{\mathrm{x}} / \mathrm{RuO}_{2}$ thin films, we combined EQCM measurements with electrolyte analysis by means of ICP-MS. During the stability tests described above, aliquots from the electrolyte were extracted for ICP-MS analysis after 150 cycles. This allowed a quantitative analysis of the amount of $\mathrm{Ru}$ and $\mathrm{Ir}$ dissolved in this time frame. Figure 6 shows the overpotential at $5 \mathrm{~mA} \mathrm{~cm}^{-2}$ (from Figure 4) together with the mass losses for $\mathrm{RuO}_{2}$ thin films, as well as that for 1 and $2 \AA$ of $\mathrm{IrO}_{\mathrm{x}}$ deposited on $\mathrm{RuO}_{2}$ thin films (Figures 6a and b, respectively). As can be observed in Figure 6b, $\mathrm{Ru}$ is responsible for the majority of the dissolved material for all samples. $\mathrm{IrO}_{\mathrm{x}}$ strongly reduces the amount of dissolved $\mathrm{RuO}_{2}$, the addition of $2 \AA \mathrm{IrO}_{\mathrm{x}}$ improves the stability of $\mathrm{RuO}_{2}$ by $\sim 72 \%$. However, we could not observe any further significant change in the stability by addition of $4 \AA \mathrm{IrO}_{\mathrm{x}}$, both activity and stability values of these two samples are very similar. Remarkably, the Ir dissolution is extremely low for the $\mathrm{IrO}_{\mathrm{x}} / \mathrm{RuO}_{2}$ as compared to the $\mathrm{Ru}$ dissolution.

Earlier work by Cherevko et al. shows that $\mathrm{IrO}_{x}$ corrosion tends to be enhanced under potentiodynamic conditions, when the electrode is cycled; conversely, the corrosion rate of $\mathrm{RuO}_{x}$ is purely a function of the applied potential, and is insensitive to cycling. ${ }^{35} \mathrm{We}$ speculate that cycling the potential may enhance the mobility of Ir; this could either occur via the formation of a solution phase species in a high oxidation state and its subsequent disproportionation, or simply via the surface movement of It atoms during oxidation and reduction cycles. The outcome would be that cycling enables the Ir atoms to reside at the undercoordinated sites.

Our results show that stable $\mathrm{IrO}_{x} / \mathrm{RuO}_{x}$ systems may be formed with $\mathrm{IrO}_{x}$ exclusively at the surface. This is consistent with the notion that the stability of the oxide material is linked to the dissolution 
potential of the surface atoms. At higher potentials, particularly at $1.8 \mathrm{~V}$ vs. RHE, the dissolution rate of Ir is significant. ${ }^{33}$ Since only a small amount is present, it all dissolves with time. The reason why this is not observed in the potential cycling experiments could be that the fraction of the time spent at a high enough potential for the Ir to dissolve is very small. Consequently, in order for all the Ir to dissolve, the cycling has to be extended for longer periods of time.
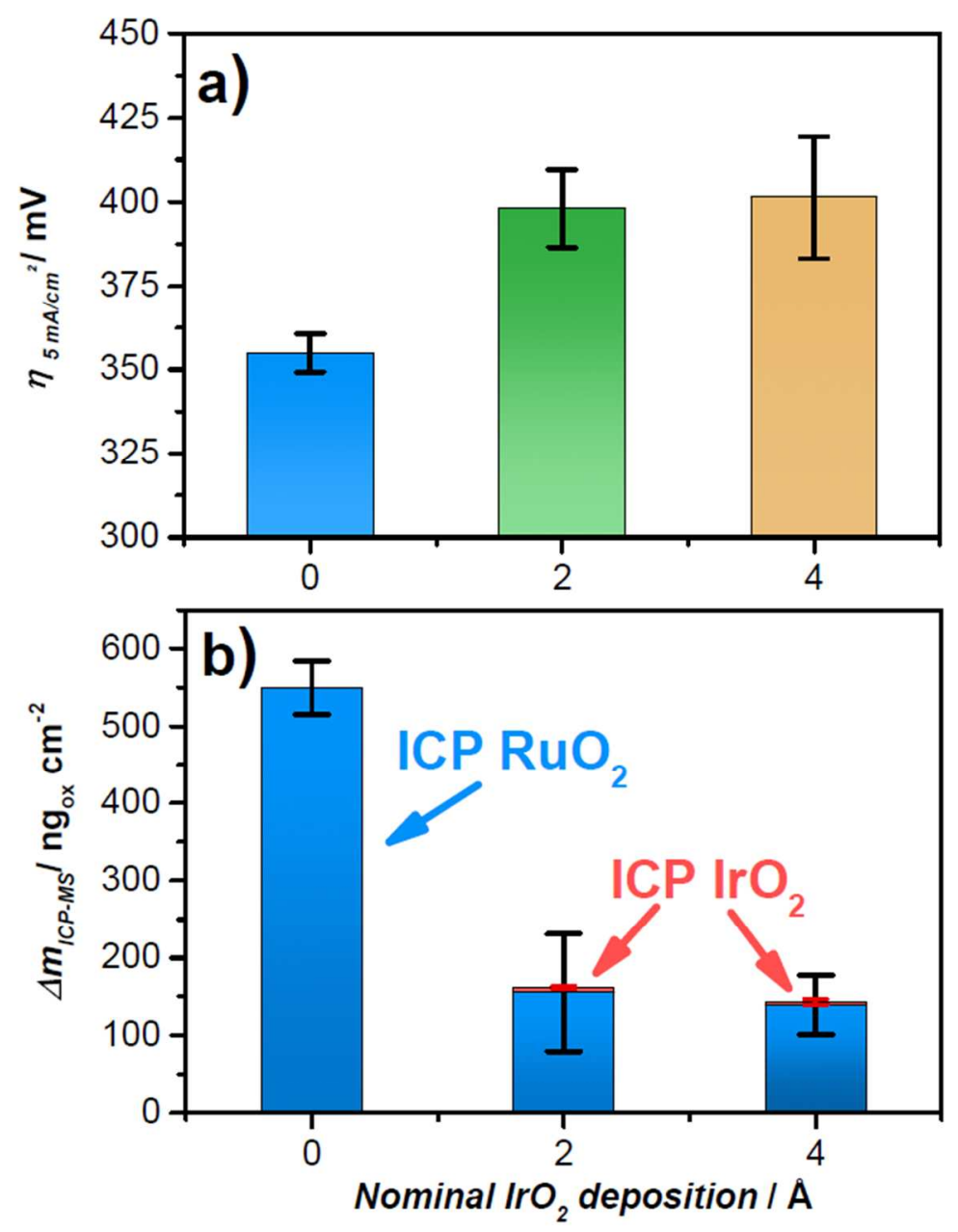

Figure 6. Activity and stability of $\mathrm{RuO}_{2}$ and $\mathrm{IrO}_{\mathrm{x}} / \mathrm{RuO}_{2}$ thin films as a function of the nominal deposition of $\mathrm{IrO}_{\mathrm{x}}$ : (a) Overpotential at $5 \mathrm{~mA} \mathrm{~cm}^{-2}$, from the first quasi stationary $\mathrm{CV}$ between 1.23 and $1.8 \mathrm{~V}$ vs. RHE at $5 \mathrm{mV} \mathrm{s}^{-1}$; (b) ICP-MS mass loss for $\mathrm{RuO}_{2}$ (in grey) and $\mathrm{IrO}_{2}$ (in blue) evaluated after 150 cycles between 1.23 and $1.80 \mathrm{~V}$ vs. RHE in $\mathrm{N}_{2}$-saturated $0.05 \mathrm{M} \mathrm{H}_{2} \mathrm{SO}_{4}$. The error bars show the standard deviation evaluated from at least four independent measurements.

\section{CONCLUSIONS}


We have presented the strategy of stabilizing $\mathrm{RuO}_{2}$ by sub-monolayer amounts of surface $\operatorname{IrO}_{x}$. EXAFS measurements revealed the formation of a rutile type $\mathrm{IrO}_{2}$ structure at the surface of the thin films. We have evaluated the stability of the thin films by combination of EQCM and ICP-MS. Sub-monolayers amounts of $\mathrm{IrO}_{x}$ at the surface of $\mathrm{RuO}_{2}$ protect the $\mathrm{Ru}$ against dissolution through the higher dissolution potential of Ir. These results can explain earlier reports in the literature, which showed that bulk mixed oxides of $\mathrm{Ir}$ and $\mathrm{Ru}$ show enhanced stability relative to pure $\mathrm{RuO}_{x},{ }^{36,42-45,72}$ more specifically, we suggest that this stabilization is due to surface phenomena. The addition of $\mathrm{IrO}_{x}$ at the surface increases the overpotential for the OER reaction, but an optimum may be reached in terms of balancing stability and activity. Furthermore, we measured low rates of Ir dissolution at $1.8 \mathrm{~V}$ vs. RHE; the protection effect is limited if only a small amount of Ir is present at the surface. This approach is useful to tune stability of active OER catalysts for PEM electrolyzers.

\section{AUTHOR INFORMATION}

\section{Corresponding Authors}

María Escudero-Escribano; e-mail: maria.escudero@chem.ku.dk

Ifan E.L. Stephens; e-mail: i.stephens@imperial.ac.uk

Ib Chorkendorff; e-mail: ibchork@fysik.dtu.dk

\section{ASSOCIATED CONTENT}

Supporting Information available: Additional experimental characterization: X-ray diffraction, scanning electron microscopy, grazing incidence extended X-ray absorption fine structure, electrochemical stability experiments and capacitance measurements.

\section{ACKNOWLEDGEMENTS}

M.E.-E. acknowledges funding from the Danish Council for Independent Research under the Sapere Aude - Research Talent Program. The Danish Ministry of Higher Education and Science is acknowledged for an EliteForsk travel grant making an extended stay at SLAC possible. Use of the Stanford Synchrotron Radiation Lightsource, SLAC National Accelerator Laboratory, is supported by the U.S. Department of Energy, Office of Science, Office of Basic Energy Sciences under Contract No. DE-AC02-76SF00515. We gratefully acknowledge the Villum Foundation V-SUSTAIN grant 9455 to the Villum Center for the Science of Sustainable Fuels and Chemicals. 


\section{REFERENCES}

(1) Chu, S.; Cui, Y.; Liu, N. The Path towards Sustainable Energy. Nat. Mater. 2016, 16 (1), 16-22.

(2) Turner, J. A. Sustainable Hydrogen Production. Science 2004, 305 (5686), 972-974.

(3) Seh, Z. W.; Kibsgaard, J.; Dickens, C. F.; Chorkendorff, I.; Nørskov, J. K.; Jaramillo, T. F. Combining Theory and Experiment in Electrocatalysis: Insights into Materials Design. Science 2017, 355 (6321), eaad4998.

(4) Hong, W. T.; Risch, M.; Stoerzinger, K. A.; Grimaud, A.; Suntivich, J.; Shao-Horn, Y. Toward the Rational Design of Non-Precious Transition Metal Oxides for Oxygen Electrocatalysis. Energy Environ. Sci. 2015, 8, 1404-1427.

(5) Fabbri, E.; Habereder, A.; Waltar, K.; Kötz, R.; Schmidt, T. J. Developments and Perspectives of Oxide-Based Catalysts for the Oxygen Evolution Reaction. Catal. Sci. Technol. 2014, 4 (11), 3800-3821.

(6) Reier, T.; Nong, H. N.; Teschner, D.; Schlogl, R.; Strasser, P. Electrocatalytic Oxygen Evolution Reaction in Acidic Environments: Reaction Mechanisms and Catalysts. Adv. Energy Mater. 2017, 7 (1), 1601275.

(7) Ayers, K. E.; Renner, J. N.; Danilovic, N.; Wang, J. X.; Zhang, Y.; Maric, R.; Yu, H. Pathways to Ultra-Low Platinum Group Metal Catalyst Loading in Proton Exchange Membrane Electrolyzers. Catal. Today 2016, 262, 121-132.

(8) Ayers, K. E.; Anderson, E. B.; Capuano, C.; Carter, B.; Dalton, L.; Hanlon, G.; Manco, J.; Niedzwiecki, M. Research Advances towards Low Cost, High Efficiency PEM Electrolysis. 2010, 33 (1), 3-15.

(9) Kotrel, S.; Bräuninger, S. Industrial Electrocatalysis. In Handbook of Heterogeneous Catalysis; Ertl, G., Knoezinger, H., Schueth, F., Weitkamp, J., Eds.; Wiley-CPH: Chichester, 2008; pp 1936-1958.

(10) Dau, H.; Limberg, C.; Reier, T.; Risch, M.; Roggan, S.; Strasser, P. The Mechanism of Water Oxidation: From Electrolysis via Homogeneous to Biological Catalysis. ChemCatChem 2010, 2 (7), 724-761.

(11) Katsounaros, I.; Cherevko, S.; Zeradjanin, A. R.; Mayrhofer, K. J. J. Oxygen Electrochemistry as a Cornerstone for Sustainable Energy Conversion. Angew. Chem. Int. Ed. 2014, 53 (1), 102121.

(12) Lee, Y.; Suntivich, J.; May, K. J.; Perry, E. E.; Shao-Horn, Y. Synthesis and Activities of Rutile $\mathrm{IrO}_{2}$ and $\mathrm{RuO}_{2}$ Nanoparticles for Oxygen Evolution in Acid and Alkaline Solutions. J. Phys. Chem. Lett. 2012, 3, 399-404.

(13) McCrory, C. C. L.; Jung, S. H.; Peters, J. C.; Jaramillo, T. F. Benchmarking Heterogeneous Electrocatalysts for the Oxygen Evolution Reaction. J. Am. Chem. Soc. 2013, 135 (45), 1697716987. 
(14) McCrory, C. C. L.; Jung, S.; Ferrer, I. M.; Chatman, S. M.; Peters, J. C.; Jaramillo, T. F. Benchmarking Hydrogen Evolving Reaction and Oxygen Evolving Reaction Electrocatalysts for Solar Water Splitting Devices. J. Am. Chem. Soc. 2015, 137 (13), 4347-4357.

(15) Diaz-Morales, O.; Raaijman, S.; Kortlever, R.; Kooyman, P. J.; Wezendonk, T.; Gascon, J.; Fu, W. T.; Koper, M. T. M.; Koper, M. T. M.; Turner, J.; et al. Iridium-Based Double Perovskites for Efficient Water Oxidation in Acid Media. Nat. Commun. 2016, 7.

(16) Seitz, L. C.; Dickens, C. F.; Nishio, K.; Hikita, Y.; Montoya, J.; Doyle, A.; Kirk, C.; Vojvodic, A.; Hwang, H. Y.; Norskov, J. K.; et al. A Highly Active and Stable IrOx/SrIrO3 Catalyst for the Oxygen Evolution Reaction. Science. 2016, 353 (6303), 1011-1014.

(17) Reier, T.; Pawolek, Z.; Cherevko, S.; Bruns, M.; Jones, T.; Teschner, D.; Selve, S.; Bergmann, A.; Nong, H. N.; Schlögl, R.; et al. Molecular Insight in Structure and Activity of Highly Efficient, Low-Ir Ir-Ni Oxide Catalysts for Electrochemical Water Splitting (OER). J. Am. Chem. Soc. 2015, 137 (40), 13031-13040.

(18) Nong, H. N.; Oh, H. S.; Reier, T.; Willinger, E.; Willinger, M. G.; Petkov, V.; Teschner, D.; Strasser, P. Oxide-Supported IrNiOx Core-Shell Particles as Efficient, Cost-Effective, and Stable Catalysts for Electrochemical Water Splitting. Angew. Chem. Int. Ed. 2015, 54 (10), 2975-2979.

(19) Neyerlin, K. C.; Gu, W. B.; Jorne, J.; Gasteiger, H. A. Study of the Exchange Current Density for the Hydrogen Oxidation and Evolution Reactions. J. Electrochem. Soc. 2007, 154 (7), B631B635.

(20) Durst, J.; Siebel, A.; Simon, C.; Hasché, F.; Herranz, J.; Gasteiger, H. A. New Insights into the Electrochemical Hydrogen Oxidation and Evolution Reaction Mechanism. Energy Environ. Sci. 2014, 7 (2), 2255-2260.

(21) Kemppainen, E.; Bodin, A.; Sebok, B.; Pedersen, T.; Seger, B.; Mei, B.; Bae, D.; Vesborg, P. C. K.; Halme, J.; Hansen, O.; et al. Environmental Science Scalability and Feasibility of Photoelectrochemical H2 Evolution: The Ultimate Limit of Pt Nanoparticle as an HER Catalyst. Energy Environ. Sci. 2015, 8, 2991-2999.

(22) Kucernak, A. R.; Zalitis, C. General Models for the Electrochemical Hydrogen Oxidation and Hydrogen Evolution Reactions: Theoretical Derivation and Experimental Results under Near Mass-Transport Free Conditions. J. Phys. Chem. C 2016, 120, 10721-10745.

(23) Benck, J. D.; Hellstern, T. R.; Kibsgaard, J.; Chakthranont, P.; Jaramillo, T. F. Catalyzing the Hydrogen Evolution Reaction ( HER ) with Molybdenum Sulfide Nanomaterials. 2014, 4 (11), 3957-3971.

(24) Vesborg, P. C. K.; Seger, B.; Chorkendorff, I. Recent Development in Hydrogen Evolution Reaction Catalysts and Their Practical Implementation. J. Phys. Chem. Lett. 2015, 6 (6), 951957.

(25) Ledendecker, M.; Mondschein, J. S.; Kasian, O.; Geiger, S.; Gçhl, D.; Schalenbach, M.; Zeradjanin, A.; Cherevko, S.; Schaak, R. E.; Mayrhofer, K. Stability and Activity of Non-NobleMetal-Based Catalysts Toward the Hydrogen Evolution Reaction. Angew. Chem. Int. Ed. 2017, 56, 9767-9771. 
(26) Rossmeisl, J.; Qu, Z.-W.; Zhu, H.; Kroes, G.-J.; Nørskov, J. K. Electrolysis of Water on Oxide Surfaces. J. Electroanal. Chem. 2007, 607 (1-2), 83-89.

(27) Suntivich, J.; May, K. J.; Gasteiger, H. a; Goodenough, J. B.; Shao-Horn, Y. A Perovskite Oxide Optimized for Oxygen Evolution Catalysis from Molecular Orbital Principles. Science 2011, 334 (6061), 1383-1385.

(28) Kuo, D.-Y.; Kawasaki, J. K.; Nelson, J. N.; Kloppenburg, J.; Hautier, G.; Shen, K. M.; Schlom, D. G.; Suntivich, J. Influence of Surface Adsorption on the Oxygen Evolution Reaction on $\mathrm{IrO}_{2}$ (110). J. Am. Chem. Soc. 2017, 139 (9), 3473-3479.

(29) Escudero-Escribano, M.; Malacrida, P.; Hansen, M. H.; Vej-Hansen, U. G.; VelazquezPalenzuela, A.; Tripkovic, V.; Schiøtz, J.; Rossmeisl, J.; Stephens, I. E. L.; Chorkendorff, I. Tuning the Activity of Pt Alloy Electrocatalysts by Means of the Lanthanide Contraction. Science. 2016, 352 (6281), 73-76.

(30) Paoli, E. A.; Masini, F.; Frydendal, R.; Deiana, D.; Schlaup, C.; Malizia, M.; Hansen, T. W.; Horch, S.; Stephens, I. E. L.; Chorkendorff, I. Oxygen Evolution on Well-Characterized MassSelected Ru and RuO 2 Nanoparticles. Chem. Sci. 2015, 6 (1), 190-196.

(31) Paoli, E. A.; Masini, F.; Frydendal, R.; Deiana, D.; Malacrida, P.; Hansen, T. W.; Chorkendorff, I.; Stephens, I. E. L. Fine-Tuning the Activity of Oxygen Evolution Catalysts: The Effect of Oxidation Pre-Treatment on Size-Selected Ru Nanoparticles. Catal. Today 2016, 262, 57-64.

(32) Kibsgaard, A. J.; Hellstern, T. R.; Choi, S.; Reinecke, B.; Jaramillo, T. Mesoporous Ruthenium / Ruthenium Oxide Thin Films : Active Electrocatalysts for the Oxygen Evolution Reaction. ChemElectroChem 2017, DOI: 10.1002/celc.201700334.

(33) Cherevko, S.; Reier, T.; Zeradjanin, A. R.; Pawolek, Z.; Strasser, P.; Mayrhofer, K. J. J. Stability of Nanostructured Iridium Oxide Electrocatalysts during Oxygen Evolution Reaction in Acidic Environment. Electrochem. Commun. 2014, 48, 81-85.

(34) Danilovic, N.; Subbaraman, R.; Chang, K.-C.; Chang, S. H.; Kang, Y. J.; Snyder, J.; Paulikas, A. P.; Strmcnik, D.; Kim, Y.-T.; Myers, D.; et al. Activity-Stability Trends for the Oxygen Evolution Reaction on Monometallic Oxides in Acidic Environments. J. Phys. Chem. Lett. 2014, 5 (14), 2474-2478.

(35) Cherevko, S.; Zeradjanin, A. R.; Topalov, A. A.; Kulyk, N.; Katsounaros, I.; Mayrhofer, K. J. J. Dissolution of Noble Metals during Oxygen Evolution in Acidic Media. ChemCatChem 2014, 6 (211), 2219-2223.

(36) Danilovic, N.; Subbaraman, R.; Chang, K. C.; Chang, S. H.; Kang, Y.; Snyder, J.; Paulikas, A. P.; Strmcnik, D.; Kim, Y. T.; Myers, D.; et al. Using Surface Segregation to Design Stable Ru-Ir Oxides for the Oxygen Evolution Reaction in Acidic Environments. Angew. Chem. Int. Ed. 2014, 53 (51), 14016-14021.

(37) Reier, T.; Oezaslan, M.; Strasser, P. Electrocatalytic Oxygen Evolution Reaction (OER) on Ru, Ir, and Pt Catalysts: A Comparative Study of Nanoparticles and Bulk Materials. ACS Catal. 2012, 2 (8), 1765-1772. 
(38) Cherevko, S.; Geiger, S.; Kasian, O.; Kulyk, N.; Grote, J.; Savan, A.; Ratna, B.; Merzlikin, S.; Breitbach, B.; Ludwig, A.; et al. Oxygen and Hydrogen Evolution Reactions on Ru , RuO 2 , Ir , and IrO 2 Thin Film Electrodes in Acidic and Alkaline Electrolytes : A Comparative Study on Activity and Stability. Catal. Today 2016, 262, 170-180.

(39) Ayers, K. E.; Dalton, L. T.; Anderson, E. B.; Transactions, E. C. S.; Society, T. E. (Invited) Efficient Generation of High Energy Density Fuel from Water. ECS Trans. 2012, 41 (33), $27-$ 38.

(40) Beer, H. B. The Invention and Industrial Development of Metal Anodes. J. Electrochem. Soc. 1980, 127, C303-C307.

(41) Trasatti, S. Electrocatalysis: Understanding the Success of DSA (R). Electrochim. Acta 2000, 45 (15-16), 2377-2385.

(42) Kötz, R.; Stucki, S. Stabilization of Ruo2 by Iro2 for Anodic Oxygen Evolution in Acid-Media. Electrochim. Acta 1986, 31 (10), 1311-1316.

(43) Angelinetta, C.; Trasatti, S.; Atanasoska, L. D.; Atanasoski, R. T. Surface-Properties of RuO2+IrO2 Mixed-Oxide Electrodes. J. Electroanal. Chem. 1986, 214 (1-2), 535-546.

(44) Owe, L. E.; Tsypkin, M.; Wallwork, K. S.; Haverkamp, R. G.; Sunde, S. Iridium-Ruthenium Single Phase Mixed Oxides for Oxygen Evolution: Composition Dependence of Electrocatalytic Activity. Electrochim. Acta 2012, 70, 158-164.

(45) Sardar, K.; Petrucco, E.; Hiley, C. I.; Sharman, J. D. B.; Wells, P. P.; Russell, A. E.; Kashtiban, R. J.; Sloan, J.; Walton, R. I. Water-Splitting Electrocatalysis in Acid Conditions Using Ruthenate-Iridate Pyrochlores. Angew. Chem. Int. Ed. 2014, 53 (41), 10960-10964.

(46) Wang, L.; Saveleva, V. A.; Zafeiratos, S.; Savinova, E. R.; Lettenmeier, P.; Gazdzicki, P.; Gago, A. S.; Friedrich, K. A. Highly Active Anode Electrocatalysts Derived from Electrochemical Leaching of $\mathrm{Ru}$ from Metallic Ir0.7Ru0.3 for Proton Exchange Membrane Electrolyzers. Nano Energy 2017, 34 (February), 385-391.

(47) Saveleva, V. A.; Wang, L.; Luo, W.; Zafeiratos, S.; Ulhaq-Bouillet, C.; Gago, A. S.; Friedrich, K. A.; Savinova, E. R. Uncovering the Stabilization Mechanism in Bimetallic RutheniumIridium Anodes for Proton Exchange Membrane Electrolyzers. J. Phys. Chem. Lett. 2016, 7 (16), 3240-3245.

(48) Kasian, O.; Geiger, S.; Stock, P.; Polymeros, G.; Breitbach, B.; Savan, A.; Ludwig, A.; Cherevko, S.; Mayrhofer, K. J. J. On the Origin of the Improved Ruthenium Stability in $\mathrm{RuO}_{2}-$ $\mathrm{IrO}_{2}$ Mixed Oxides. J. Electrochem. Soc. 2016, 163 (11), F3099-F3104.

(49) Binninger, T.; Mohamed, R.; Waltar, K.; Fabbri, E.; Levecque, P.; Kötz, R.; Schmidt, T. J. Thermodynamic Explanation of the Universal Correlation between Oxygen Evolution Activity and Corrosion of Oxide Catalysts. Sci. Rep. 2015, 5 (February), 12167.

(50) Man, I. C. Theoretical Study of Electro-Catalysts for Oxygen Evolution; Technical University of Denmark (DTU), 2011. 
(51) Pourbaix, M. Atlas of Electrochemical Equilibria in Aqueous Solutions, Second.; National Association of Corrosion Engineers: Houston, Texas, 1974.

(52) Spoeri, C.; Kwan, J. T. H.; Bonakdarpour, A.; Wilkinson, D.; Strasser, P. The Stability Challenges of Oxygen Evolving Electrocatalysts: Towards a Common Fundamental Understanding and Mitigation of Catalyst Degradation. Angew. Chem. Int. Ed. 2016, 5994-6021.

(53) Frydendal, R.; Paoli, E. A.; Knudsen, B. P.; Wickman, B.; Malacrida, P.; Stephens, I. E. L.; Chorkendorff, I. Benchmarking the Stability of Oxygen Evolution Reaction Catalysts: The Importance of Monitoring Mass Losses. ChemElectroChem 2014, 1 (12), 2075-2081.

(54) Wu, C. H.; Weatherup, R. S.; Salmeron, M. B. Probing Electrode/electrolyte Interfaces in Situ by X-Ray Spectroscopies: Old Methods, New Tricks. Phys. Chem. Chem. Phys. 2015, 17 (45), 30229-30239.

(55) Topalov, A. A.; Katsounaros, I.; Auinger, M.; Cherevko, S.; Meier, J. C.; Klemm, S. O.; Mayrhofer, K. J. J. Dissolution of Platinum: Limits for the Deployment of Electrochemical Energy Conversion? Angew. Chem. Int. Ed. 2012, 51 (50), 12613-12615.

(56) Kuznetsova, E.; Cuesta, A.; Thomassen, M. S.; Sunde, S. Identification of the Byproducts of the Oxygen Evolution Reaction on Rutile-Type Oxides under Dynamic Conditions. J. Electroanal. Chem. 2014, 728, 102-111.

(57) Tao, F.; Salmeron, M. In Situ Studies of Chemistry and Structure of Materials in Reactive Environments. Science. 2011, 331 (6014), 171-175.

(58) Subbaraman, R.; Tripkovic, D.; Chang, K.-C.; Strmcnik, D.; Paulikas, A. P.; Hirunsit, P.; Chan, M.; Greeley, J.; Stamenkovic, V.; Markovic, N. M. Trends in Activity for the Water Electrolyser Reactions on 3d M(Ni,Co,Fe,Mn) Hydr(oxy)oxide Catalysts. Nat. Mater. 2012, 11 (6), 550-557.

(59) Sanchez Casalongue, H. G.; Ng, M. L.; Kaya, S.; Friebel, D.; Ogasawara, H.; Nilsson, A. In Situ Observation of Surface Species on Iridium Oxide Nanoparticles during the Oxygen Evolution Reaction. Angew. Chem. Int. Ed. 2014, 126 (28), 7297-7300.

(60) Thomas, J. M.; Hernandez-Garrido, J. C. Probing Solid Catalysts under Operating Conditions: Electrons or X-Rays? Angew. Chem. Int. Ed. 2009, 48, 3904-3907.

(61) Salmeron, M.; Schlogl, R. Ambient Pressure Photoelectron Spectroscopy: A New Tool for Surface Science and Nanotechnology. Surf. Sci. Rep. 2008, 63 (4), 169-199.

(62) Russell, A. E.; Rose, A. X-Ray Absorption Spectroscopy of Low Temperature Fuel Cell Catalysts. Chem. Rev. 2004, 104 (10), 4613-4636.

(63) Pedersen, A. F.; Escudero-Escribano, M.; Sebok, B.; Bodin, A.; Paoli, E.; Frydendal, R.; Friebel, D.; Stephens, I. E. L.; Rossmeisl, J.; Chorkendorff, I.; et al. Operando XAS Study of the Surface Oxidation State on a Monolayer $\mathrm{IrO}_{\mathrm{x}}$ on $\mathrm{RuO}_{\mathrm{x}}$ and $\mathrm{Ru}$ Oxide Based Nanoparticles for Oxygen Evolution in Acidic Media. J. Phys. Chem. B 2017, DOI: 10.1021/acs.jpcb.7b06982

(64) Frydendal, R.; Paoli, E. A.; Chorkendorff, I.; Rossmeisl, J.; Stephens, I. E. L. Toward an Active and Stable Catalyst for Oxygen Evolution in Acidic Media: Ti-Stabilized MnO2. Adv. Energy 
Mater. 2015, 5 (22).

(65) Friebel, D.; Miller, D. J.; O’Grady, C. P.; Anniyev, T.; Bargar, J.; Bergmann, U.; Ogasawara, H.; Wikfeldt, K. T.; Pettersson, L. G. M.; Nilsson, A. In Situ X-Ray Probing Reveals Fingerprints of Surface Platinum Oxide. Phys. Chem. Chem. Phys. 2011, 13 (1), 262-266.

(66) Paoli, E. A. Activity and Stability of RuOx Based Electrocatalysts for the Oxygen Evolution Reaction. Technical University of Denmark (DTU), 2014.

(67) Iro, R. Orientation-Dependent Oxygen Evolution Activities of. 2013, 135 (45), 142386.

(68) Bolzan, A. A.; Fong, C.; Kennedy, B. J.; Howard, C. J. Structural Studies of Rutile-Type Metal Dioxides. Acta Crystallogr. 1997, B53, 373-380.

(69) Angelinetta, C.; Trasatti, S.; Atanasoska, L. D.; Minevski, Z. S.; Atanasoski, R. T. Effect of Preparation on the Surface and Electrocatalytic Properties of Ruo2 + Iro2 Mixed-Oxide Electrodes. Mater. Chem. Phys. 1989, 22 (1-2), 231-247.

(70) Over, H.; Seitsonen, A. P.; Lundgren, E.; Smedh, M.; Andersen, J. N. On the Origin of the Ru3d5/2 Satellite Feature from RuO2(110). Surf. Sci. 2002, 504, L196-L200.

(71) Trasatti, S.; Petrii, O. A. Real Surface-Area Measurements in Electrochemistry. J. Electroanal. Chem. 1992, 327 (1-2), 353-376.

(72) Siracusano, S.; Van Dijk, N.; Payne-Johnson, E.; Baglio, V.; Aricò, A. S. Nanosized IrOx and IrRuOx Electrocatalysts for the O2 Evolution Reaction in PEM Water Electrolysers. Appl. Catal. B Environ. 2015, 164, 488-495. 


\section{TOC Graphic}

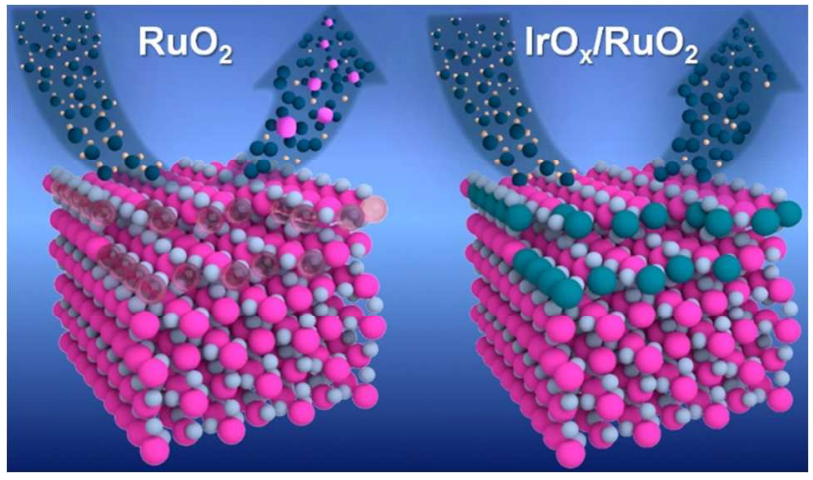

Illustration of the oxygen evolution reaction and ruthenium dioxide corrosion on $\mathrm{RuO}_{2}(110)$ surface (left) and on the same surface with the under-coordinated sites decorated with $\operatorname{IrO}_{\mathrm{x}}$ (right). 